\title{
Sociocultural Theory and its application to CALL: A study of the computer and its relevance as a mediational tool in the processes of collaborative activity.
}

\author{
Gabriela Adela Gánem Gutiérrez, University of Essex
}

\section{Abstract}

This study in the field of Second Language Acquisition (SLA) was conducted in a Spanish as a foreign language classroom. The study investigates dyadic face-to-face collaborative dialogue at the computer from a Sociocultural perspective. Protocols for analysis were obtained by the transcription of audio recordings of (12) dyads/triads completing three tasks in two mediums of implementation, computer and non-computerbased. By comparing learners' activity in the two mediums through microgenetic analysis (i.e., developmental analysis), we were able to study some specific ways in which the computer influenced the course of interaction. Specifically, the aim of the study was to investigate the value of the tasks as pedagogical instruments to support collaborative activity in the foreign language classroom; the value of collaborative activity as a source for possible restructuring of interlanguage (i.e., microgenesis); and the impact of the computer as a mediational tool in the processes of collaborative activity. Results confirm 1) the three tasks support high degrees of collaborative activity - albeit qualitatively different; 2) language can - sometimes simultaneously - be deployed by learners both as a 
means of communication and as a cognitive tool to achieve linguistic development; 3) the presence of the computer seems to change the nature of collaborative activity.

\section{Introduction}

A fundamental premise from a Sociocultural approach to language learning is the notion of knowledge being social and created in interaction. According to Vygotsky (1978), cognitive development appears first in the inter-psychological plane and it is then appropriated by the individual. The processes undergone in inter-psychological activity are mediated by tools, either physical and/or symbolic, language being the most pervasive of these. Social interaction is a means to achieve development that enables appropriation/internalisation "through a dynamic transformative process called microgenesis” (Wertsch, 1985 in Ohta, 2000:54). The learning process I am referring to as microgenesis can sometimes be observed while learners engage in dialogic communication, and can thus be studied within the situated activity in which it occurs.

Framed within this approach to language learning, the main objective of the investigation reported in this article was to study collaborative activity across three tasks in two modes of implementation (computer versus paper) in order to address the following questions: 
1. To what degree do the three different tasks in the two mediums of implementation - computer and non-computer based - support collaborative activity in the classroom?

2. To what degree do participants engage in High Quality Collaboration (HQC)? ${ }^{1}$

3. What is the effect of the computer as a mediational tool in the processes of collaborative activity?

After establishing the theoretical underpinnings of the study in the section entitled "Sociocultural Theory", I provide an overview of the context and research methods deployed (see "the study" below). The comparative nature of the methodology employed aims to identify specific patterns and characteristics of interaction influenced by the medium. In other words, the comparison between computer and paper modes moves away from general questions about the supremacy of one mode over another. The aim is to explore specific tasks implemented in a particular context to identify possible strengths and weaknesses brought about by the mediational tool. A second aspect to bear in mind is the need in the field to find, test, and refine the methodological constructs required to adequately investigate collaborative activity in the classroom. In an effort to contribute to the fulfilment of this need, I introduce the concept of High Quality Collaboration (HQC) (see "analytical procedures” below), a methodological construct grounded in the data that facilitates both qualitative and quantitative data analyses. This paper forms part of a wider study of the processes of collaborative activity in computer-mediated tasks (cf. author, 2004).

\footnotetext{
${ }^{1}$ For the purposes of the present study I have defined High Quality Collaboration as collaboration where learners, working within a zone of proximal development (ZPD), are able to co-construct language related knowledge. For further explanation see "Analytical procedures" section below.
} 


\section{Sociocultural Theory}

Sociocultural Theory is rooted in the "Vygotskian argument that knowledge is social and is created in interaction” (Daniels, 1993). The Sociocultural approach to learning differs from other cognitive approaches in that it does not accept that knowledge originates and develops exclusively inside the individual mind by means of biological mechanisms and internal processes. Vygotsky accorded learning a fundamentally social nature. Thus learning is a mediated process that originates in societal activity. The learning process “...can sometimes be traced visibly in the course of talk between expert and novice. This local, contextualized learning process is labelled microgenesis" (Mitchell and Myles, 2004:198). From a Sociocultural perspective there are three important issues to be considered in relation to learning, specifically in the classroom: instruction, agency, and situatedness. The role of instruction is at the core of this approach. Instruction is essentially a collaborative act where zones of proximal development ${ }^{2}$ are created by the participants, that is agents with their own social perspectives and histories, goals, attitudes, etc. The situated quality of learning highlights that circumstance is a pervasive aspect that has to be carefully considered since "learning unfolds in different ways under different circumstances” (Donato, 2000: 47).

Due to the complexity of agency during activity and the pervasive influence of circumstance upon it, it is possible that activities change and evolve even in the span of a

\footnotetext{
${ }^{2}$ In Vygotsky's words, the ZPD is "the discrepancy between a child's actual mental age and the level he reaches in solving problems with assistance indicates the zone of proximal development" (Vygotsky, 1986:187). Lantolf (2000) has interpreted the zone of proximal development (ZPD) as a metaphor for the "site where social forms of mediation develop...for observing and understanding how mediational means are appropriated and internalized" (2000:16-17).
} 
few moments. Furthermore, although a group of participants might be involved in performing a particular task, this does not mean that they are all engaged in the same activities which, in turn, has major implications in the language classroom since it is students that shape both the goals and outcomes of tasks (see Lantolf and Appel,1994; Donato, 2000; and Roebuck, 2000). These theoretical insights have been corroborated by investigations into SLA tasks carried out by researchers such as Coughlan and Duff who suggest that tasks are no more than "behavioural blueprints" (1994: 175) for learners to engage in their own particular activity. Not only do their protocols show how five different learners conceptualise the same task differently, but also how the same learner re-interprets the same task in a different way when asked to perform it again over a period of time. Their work leads them to conclude that on the one hand "a linguistic event never duplicates a past one, and can never be truly replicated in the future” and on the other hand, although "the task or blueprint may be the same, the activity it generates will be unique” (Coughlan and Duff, 1994:190).

\subsection{Collaborative dialogue}

From a Sociocultural perspective, the cognitive processes involved in the production of output that might lead to language development - e.g. through focusing on form; by "pushing" learners to get involved in more mental efforts and so, process language at a deeper level; by moving from semantic to strategic levels in order to achieve accurate production, etc. (cf. Swain, 1995) - are first realised in the inter-mental plane and then internalised. It is through and by means of dialogue that noticing, hypothesis testing, and 
reflective metalinguistic talk can occur (Swain, 1997). However, not all dialogue is equally conducive to cognitive and linguistic development. Researchers like Donato (1994), Swain (1997), Swain and Lapkin (2001), and Roschelle and Teasley (1995) have identified collaborative dialogue that emerges from learners' interactions when engaged in problem-solving activity as the kind of interaction that can potentially lead to the coconstruction of linguistic development through the process of internalisation ${ }^{3}$. In Swain's words, collaborative dialogue "is where language use and language learning can co-occur. It is language use mediating language learning. It is cognitive activity and social activity” (Swain, 2000: 97). Crucially, engagement in collaborative dialogue does not necessarily take place because learners misunderstand each other and have to “negotiate for meaning” ( $c f$. Long, 1983; Pica, 1994), but because they notice a linguistic problem and try to find out solutions to solve it. Central to this perspective is the issue of agency, to be able to understand collaborative activity we also need to understand "how the learner relates himself to the learning task and how this relationship is based on the learner's self-constructed goals” (Donato, 1988: 5).

\footnotetext{
${ }^{3}$ The process of transition from inter-mental activity to intra-mental activity is called appropriation -or internalisation (cf. Frawley, 1997).
} 


\section{The study}

\subsection{Context, learners, and research design}

The study was conducted in a Spanish as a foreign language classroom for undergraduate students throughout an academic semester; the class was conducted largely in the target language, although English was sporadically used. The participants were 11 females and 7 males in their late teens/early twenties. Their level of Spanish was Intermediate, which corresponds to a grade $\mathrm{C}$ in ' $\mathrm{A}$ ' level Spanish, the national qualification within the British Education context taken at the end of secondary schooling. The study focused upon the following grammatical structures as part of the course programme being taught by the author: personal pronouns to include subject, direct and indirect object, prepositional and reflexive pronouns; infinitive verbs; radical changing verbs; and 'ser' versus 'estar' (the two Spanish verbs for 'to be'). None of these structures were expected to be new for the students although, as the pre-test showed, they had indeed problems with their use.

The main instrument for data collection was the task. Learners agreed to be audiorecorded while performing language tasks in pairs/trios for the purposes of research. Data were collected by the teacher-researcher during weeks 5, 8, and 11 out of a 12-week programme. Due to the fact that data collection was implemented as part of the students' Spanish class, participants were free to decide whom they wanted to work with since this is what normally happens in all the Spanish sessions at the University and it was not in conflict with the study design. The recorded data (5 hrs 20 min of learners' interaction) were transcribed to produce protocols for data analysis. The three tasks, described below, 
were implemented in two modes: computer-based and paper-based. The main purpose for comparing the two modes of implementation was to facilitate the study of the computer pervasiveness in activity (cf. Author 2003; 2004). For each of the tasks, participants were divided into two groups. Half of the dyads/trios accomplished a Computer-Assisted Language Learning (CALL) task and half a Paper task. Students were given the opportunity to work alternately between the two modes throughout the three tasks. In other words, participants that worked on CALL mode in task 1 were then asked to work on Paper mode in task 2 and so on. The study corpus comprised of 12 protocols (2 paperbased and 2 computer-based for each of the three research tasks), and were managed and analysed with the assistance of two software packages: N5 and Excel. Students also took a grammar test at the beginning and at the end of the study (pre-post-tests respectively) in order to evaluate progress in relation to the grammatical structures mentioned above (for a full report refer to Author 2004).

\subsection{The tasks}

Three problem-solving tasks were specifically designed as the main data collection instrument to elicit and record the processes of collaboration undergone by participants while accomplishing them either at the computer (CALL tasks) or in a paper version (Paper tasks). The main methodological purpose of the tasks as instruments for data collection was to provide the participants with an opportunity to engage in interpsychological activity by collaborating to complete them. Using the capabilities of HotPotatoes, feedback and help from the computer were provided in various degrees and three different ways: clues, hints, and a correction button. Clues were selectively 
provided by means of a question mark button next to a blank; when clicking this button students would obtain clues in the top frame of the screen. Hints were available in selected frames; this button was always positioned at the bottom of the screen and students would get letters for the words required just by putting the cursor in the desired blank and clicking the hints button. The correction button, always located at the bottom of the page and provided in every frame, would integrate correct answers to the text, but marking them by means of bold type; incorrect gaps would be cleared out for students to continue working on them. The teacher-researcher was always available to everyone whether they were working at the computer or on the paper versions of the tasks. In general, there was more help available as the task progressed to encourage the participants to collaborate and get help from each other before resorting to the machine. Learners working on the paper tasks received feedback and help from the teacherresearcher when requested.

\section{Task 1: Professionals Today}

The first task (see appendix 1) consisted of three parts: 1) a discussion about the world of work, implemented through a hierarchical exercise where participants had to organise concepts such as 'power' and 'money' according to what they considered more or less important in the world of work; 2) an interview reconstruction of a Spanish professional talking about his views of the world of work; and 3) creation of a document to express participants' own views about the topic, but in the context of the UK. The goals of this task were on the one hand, to provide a space for discussion and collaboration to reach 
common agreement and express their own thoughts and, on the other hand, to practise personal pronouns in a contextualised way.

\section{Task 2: Gifted Daughters}

Task two (see appendix 2) was a traditional problem-solving task (trail quiz) where participants are given clues that will help them solve the problem posited. This task consisted of a macro-task: finding out which language and which musical instrument belonged to which of five sisters; and five embedded micro-tasks that focused on grammar (personal pronouns and infinitive verbs). The micro-tasks were implemented as gap-filling, translation, jumbled sentences, and caption writing. In other words, the dyads had to solve a problem by collecting the necessary five pieces of information, the object for this being the encouragement of metacognitive talk which is believed to stimulate individuals, provide them with an infrastructure to negotiate development, take and manage control of their activity and learning, and guide them through the tasks (see Hoven 1999; Swain 2000; Ohta 2001). Each piece of information was provided to them by the computer - or teacher - after completing a micro-task based on grammar. This task was also intended to bring about metalinguistic talk in relation to personal pronouns and use of infinitive verbs in Spanish.

\section{Task 3: Mexico City}

Finally, the third task (see appendix 3) was an adaptation of 'dictogloss' (Kowal and Swain 1997: 295 and Swain and Lapkin 2001: 101) which is described as ‘...a procedure that encourages students to reflect on their own output. In this procedure, a short, dense 
text is read to the learners at normal speed; while it is being read, students jot down familiar words and phrases; the learners work together in small groups to reconstruct the text from their shared resources...' (Kowal and Swain 1997: 295). The purpose of implementing this type of task in the study was twofold: a) to promote the production of metalinguistic talk while providing learners with practice on 'ser' and 'estar' since these verbs where necessary for the successful reconstruction of the text; b) to compare the effects of the computer (as opposed to the Paper version) in terms of creativity and accuracy.

In the CALL version of this task participants read the text provided on the right hand side of the computer screen instead of listening to it (as done in 'dictogloss'), they were not allowed to typewrite while the text was on the screen. The Paper version of this task consisted of three pages: one with the instructions, another one with the text, and a third one with the title of the text and blanks for learners to reconstruct it; as in the CALL version, punctuation marks were provided. The text was designed for learners to focus on the verbs 'ser' and 'estar'. Intermental activity was expected to produce metacognitive and metalinguistic talk.

To summarise, the three tasks designed for collection of data in this study provided the students with a twofold general objective. On the one hand, students had the specific aim of completing the problem solving phase of the tasks, and on the other hand, they were able to focus on form by working on the grammatical structures that were part of the exercises embedded in the tasks. 
Figure 1: Summary of the tasks as a tool for data collection

\begin{tabular}{|c|c|c|c|c|}
\hline TASK & PROCEDURE & MAIN GOALS & $\begin{array}{l}\text { EXPECTED } \\
\text { INTER- MENTAL } \\
\text { ACTIVITY }\end{array}$ & $\begin{array}{l}\text { PROGRAMME } \\
\text { TYPE FOR CALL } \\
\text { VERSION }\end{array}$ \\
\hline $\begin{array}{l}1 . \\
\text { Professionals } \\
\text { Today. }\end{array}$ & $\begin{array}{l}\text { 1. Discussion -aided by } \\
\text { computer- about the } \\
\text { world of work and } \\
\text { relationships. } \\
\text { 2. Cloze exercise to } \\
\text { complete interview with } \\
\text { a Spanish professional } \\
\text { about perceptions of } \\
\text { work and relationships. } \\
\text { 3. Creation of a } \\
\text { document to express } \\
\text { students' own views } \\
\text { towards either } \\
\text { professional life in } \\
\text { Spain, taking into } \\
\text { account the views in the } \\
\text { interview, or work life } \\
\text { in the UK. }\end{array}$ & $\begin{array}{l}\text { To practise } \\
\text { personal pronouns. } \\
\text { To discuss and } \\
\text { express their views } \\
\text { on the task topics. } \\
\text { To create a } \\
\text { document in order } \\
\text { to synthesise their } \\
\text { discussion. }\end{array}$ & $\begin{array}{l}\text { Communication } \\
\text { for meaning. } \\
\text { Metalinguistic talk. } \\
\text { Metacognitive } \\
\text { activity (e.g. } \\
\text { planning) }\end{array}$ & $\begin{array}{l}\text { Drag-drop } \\
\text { programme } \\
\text { implemented with } \\
\text { HotPotatoes } \\
\text { Partial- deletion } \\
\text { programme. } \\
\text { Webpage generator } \\
\text { GoLive. }\end{array}$ \\
\hline $\begin{array}{l}\text { 2. Gifted } \\
\text { Daughters: } \\
\text { Problem- } \\
\text { solving task: } \\
\text { variation on a } \\
\text { trail quiz. }\end{array}$ & $\begin{array}{l}\text { Students have to solve a } \\
\text { problem by collecting } \\
\text { the necessary } \\
\text { information ( } 5 \text { pieces). } \\
\text { Each piece of } \\
\text { information is provided } \\
\text { to them by the computer } \\
\text { when they successfully } \\
\text { complete a grammar } \\
\text { task. }\end{array}$ & $\begin{array}{l}\text { To solve a } \\
\text { problem. } \\
\text { To practise } \\
\text { personal pronouns, } \\
\text { and the infinitive. }\end{array}$ & $\begin{array}{l}\text { Metacognitive talk } \\
\text { leading to the } \\
\text { solution of the } \\
\text { problem (e.g. } \\
\text { planning, and } \\
\text { negotiation) } \\
\text { Metalinguistic talk. }\end{array}$ & $\begin{array}{l}\text { HotPotatoes to } \\
\text { produce cloze, } \\
\text { translation, } \\
\text { matching and } \\
\text { jumbled sentence } \\
\text { exercises. } \\
\text { GoLive. }\end{array}$ \\
\hline $\begin{array}{l}\text { 3. Mexico } \\
\text { City: Text re- } \\
\text { construction, } \\
\text { a variation on } \\
\text { Dictogloss }\end{array}$ & $\begin{array}{l}\text { 1. Students read a short } \\
\text { text on the screen that } \\
\text { will disappear after } 60 \\
\text { seconds. (They have } \\
\text { two opportunities to } \\
\text { read the text.) } \\
\text { 2. Students collaborate } \\
\text { on reconstruction of the } \\
\text { text, following a cloze } \\
\text { format. } \\
\text { 3. Students write } \\
\text { together a similar text, } \\
\text { but this time about } \\
\text { London, using a word } \\
\text { processor. }\end{array}$ & $\begin{array}{l}\text { To work on "Ser” } \\
\text { y "Estar” by } \\
\text { reconstructing a } \\
\text { text in which these } \\
\text { verbs are essential. } \\
\text { To create a } \\
\text { document that will } \\
\text { reflect their } \\
\text { personal } \\
\text { perceptions about } \\
\text { London. To } \\
\text { negotiate the kind } \\
\text { of information to } \\
\text { be included in } \\
\text { their text. }\end{array}$ & $\begin{array}{l}\text { Metacognitive talk: } \\
\text { planning how to } \\
\text { tackle the task. } \\
\text { Metalinguistic talk. } \\
\text { Communication } \\
\text { for meaning. }\end{array}$ & $\begin{array}{l}\text { HotPotatoes. } \\
\text { GoLive. }\end{array}$ \\
\hline
\end{tabular}




\subsection{Analytical Procedures: Interaction foci and Collaborative Episodes}

Analysis focused on the study of patterns emerging from the data on the one hand, but also on the study of behaviour that might be unique to certain dyads/trios on the other. The aim was to better understand the degree to which certain tasks and task features might be considered as blueprints in terms of being pedagogical tools, and what the specificity of the computer might be throughout the processes of collaborative activity.

\subsubsection{First level of analysis: Foci of interaction}

The degree of collaboration in the study refers to a dual dimension during interaction, a) the social relationships developed among the participants, i.e., did they collaborate, compete, argue, etc. and b) what the focus of those social relationships was, e.g. the task, the target language, social conversation. In order to assess and compare the degree of collaboration and foci of interaction among tasks and between mediums, the data were coded for language related talk (following Swain and Lapkin, 1995, any talk about the language students are producing, any language-related questioning, or when they other or self-correct their language production); task related talk (talk specifically related to task implementation, i.e. about content, problem-solving activity, or simply carrying out the task without focusing on the target language); and off-task talk. Subsequently, percentages of the foci of talk across the data were calculated in order to gain a quantitative perspective of the relationships between type of task and medium of 
implementation, and the foci of talk supported. These percentages were calculated taking the text unit ${ }^{4}$ as the unit for analysis. The text unit was adopted for this kind of quantification rather than the speech turn, because that is the unit utilised by N5, the software package through which data were managed.

\subsubsection{Second level of analysis: High Quality Collaboration (HQC)}

Once all the language related talk was identified throughout the data, it was further segmented and coded into episodes following Swain (1998: 70) who defines a language related episode (LRE) as "any part of a dialogue in which students talk about the language they are producing, question their language use, or other -or self-correct”, and which focuses on one "language item only" (Fortune and Thorp, 2001: 146).

A further construct for data analysis was High Quality Collaboration (HQC). For the purposes of the present study I have defined High Quality Collaboration as collaboration where learners, working within a zone of proximal development (ZPD), are able to coconstruct language related knowledge. This can be achieved through what Donato (1994) has called "collective scaffolding”, which is collaboration where several "novices" are able to empower each other by achieving as a dyad/group what they could not achieve individually; or by an individual "expert” providing the necessary assistance required by a "novice" to achieve any kind of language related development. In my view, and as the definition of HQC implies, microgenesis episodes (MGEs), i.e. episodes where the learning process towards internalisation can be perceptible to the researcher's eye, are

\footnotetext{
${ }^{4}$ In N5 a line is a text unit "of at most 74 characters in length (including spaces)" QSR International Pty Ltd@ 1980-2000. A text unit, therefore, does NOT necessarily correspond to a speech turn.
} 
not the exclusive manifestation of learners working within their ZPDs. This metaphoric socio-cognitive space is also "inhabited" by other LREs where learners achieve, through collaboration, language constructions which appeared to be beyond their individual capabilities as evident at the beginning of the LRE in question, but where the process of change as such is not overt. Figure 2 provides examples of the two kinds of LREs I have categorised as HQC. 
Figure 2: High Quality Collaboration

\begin{tabular}{|c|c|}
\hline $\begin{array}{c}\text { microgenetic LRE } \\
\text { (excerpt from computer-based task 2) }\end{array}$ & $\begin{array}{c}\text { non-microgenetic LRE } \\
\text { (excerpt from computer-based task 1) }\end{array}$ \\
\hline $\begin{aligned} 129 \mathrm{H}: & \text { pero continuo (.) es el= } \\
& \quad \text { (but carried on (.) it's the }=\text { ) }\end{aligned}$ & $\begin{array}{ll}65 \quad \text { E: } & \text { ehhe "qué piensan ustedes acerca de } \\
& \text { lo que es importante" ((fading voice } \\
& \text { while reading instructions)) } \\
& \text { ehhe "what do you think is } \\
& \text { important" ((fading voice while } \\
& \text { reading instructions)) }\end{array}$ \\
\hline $\begin{aligned} 130 \mathrm{~h}: \quad & =\text { no s no estoy seguro }(.) \text { continuo }= \\
& (=I ' m \text { no I'm not sure }(.) \text { carried on })\end{aligned}$ & $\begin{array}{lll}66 & \text { M: } & \text { um (.) ah (.) LE parece? ((pause)) o } \\
& \text { la A } \\
& \text { um (.) ah (.) to her ((in Spanish } \\
& \text { indirect personal pronoun “le”)) it } \\
& \text { seems? ((pause)) or the a }\end{array}$ \\
\hline $\begin{array}{lll}131 & \mathrm{H}: & =\text { [gerundio } \\
& & (=[\text { gerund })\end{array}$ & $\begin{aligned} 67 \quad \mathrm{E}: & \text { a a mi (.) compañera ((pause)) LE si } \\
& \text { to to my (.) classmate ((pause)) le } \\
& \text { yes }\end{aligned}$ \\
\hline $\begin{array}{lll}132 & \text { h: } & \text { [a leer? } \\
& \text { ( [to read?) }\end{array}$ & $\begin{array}{lll}68 \quad \mathrm{M}: & \text { le parece? [si le parece } \\
& \text { to her it seems? [yes to her it seems } \\
& \text { ((using correct personal pronoun } \\
& \text { "le")) }\end{array}$ \\
\hline $\begin{array}{rrr}133 & \mathrm{H}: \quad \begin{array}{l}\text { después de [continuar } \\
\\
\end{array} \\
& \text { (after to [continue) }\end{array}$ & \begin{tabular}{ccc}
69 & $\mathrm{E}:$ & \multicolumn{1}{c}{ [le parece porque es (.) } \\
& indirecto ((pause)) que la \\
& inteligencia gencia es [más? \\
& \multicolumn{1}{c}{ [to her it seems because } \\
& it's (.) indirect ((pause)) that \\
intelligence is [more?
\end{tabular} \\
\hline $\begin{array}{cc}134 \text { h: } & \text { [continuar leyendo } \\
& \text { leer leyendo (.) leyendo?= } \\
& \text { ([to continue reading to } \\
& \text { read reading (.) reading?) } \\
\end{array}$ & \\
\hline 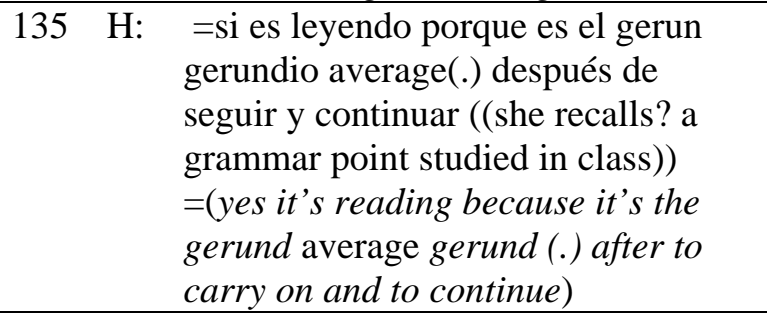 & \\
\hline
\end{tabular}

In the microgenetic episode we are able to witness how Henry (h) progresses from being unable to produce the correct form in turns 130 and 132 to gaining control of the form and producing it correctly in turn 134 as a result of Hena's intervention $(\mathrm{H})$ and the collective experience, which enables them to engage in a pedagogic routine. In the non- 
microgenetic example, on the other hand, the correct form is produced by Mina in turn 66, but she shows uncertainty (turns 66 and 68). Ellen takes Mina's suggestion and hesitation (t66) as a point of departure for reflective consideration (t67) that culminates in metalinguistic consolidation for both participants (t69). Although change is not "visible" in the episode, knowledge construction and consolidation are, as learners empower each other within a ZPD.

Methodologically therefore, the process of categorisation of HQC is simultaneously intertwined with qualitative analysis. The method was rooted in the work and notions conceptualised in fields such as psychology, education, and SLA, but was developed as analysis became more grounded in the data. For validity and reliability purposes, the process for developing the coding scheme entailed various stages where categories were defined, checked, and refined until we (supervisor and researcher) were confident the system worked and could be applied to the data reliably, e.g. two protocols were independently coded and results compared. The relevance of the computer was assessed throughout all the stages of analysis as an integral aspect of the phenomena being investigated. However, the computer's impact was specifically studied through comparisons across the data in relation to its effect on talk foci, i.e. language related talk, task related talk, and off-task conversation, as well as to the use of semiotic mechanisms (such as repetition, use of L1, reading aloud) mediating CALL activity (for the latter see Author, 2004). These analyses were carried out to inform us on possible advantages or drawbacks of using the computer to implement specific types of tasks. 


\section{Results and Discussion}

All the participants in the study showed willingness to work as part of a pair/trio, no disputational talk or un-collaborative behaviour was identified in any of the transcribed protocols. Across the three tasks, there were no striking differences between the percentage amounts of talk for language related matters, task related activity, and off-task activity. Learners working on paper engaged in $4 \%$ more language related talk than people working at the computer, with virtually no difference (1\% more on paper) in terms of task related talk. Students at the computer engaged in $7 \%$ off-task conversation whereas paper-based learners in only $2 \%$. The medium influenced off-task conversation in that some of the computer off-task talk was caused by distractions directly related to the computer (for example one dyad had technical problems with a text that was not meant to be visible on the screen), and paper-based learners normally engaged in off-task conversation while having to wait for the teacher to check their work. As Table 1 and Table 2 show there are more important medium related differences across individual tasks both in relation to talk foci and HQC collaboration.

Table 1: Percentages of talk foci between mediums

\begin{tabular}{|l|l|l|l|l|l|l|}
\hline $\begin{array}{l}\text { \% of text } \\
\text { units }\end{array}$ & CT1 & PT1 & CT2 & PT2 & CT3 & PT3 \\
\hline $\begin{array}{l}\text { Language } \\
\text { Related } \\
\text { Talk }\end{array}$ & 59.5 & 67 & 66.5 & 55.5 & 17.5 & 34 \\
\hline $\begin{array}{l}\text { Task } \\
\text { Related } \\
\text { Talk }\end{array}$ & 31 & 33 & 29.5 & 41.5 & 75 & 64.5 \\
\hline $\begin{array}{l}\text { Off - Task } \\
\text { Talk }\end{array}$ & 9.5 & 0 & 4 & 3 & 7.5 & 1.5 \\
\hline
\end{tabular}


Table 2: HQC comparison

\begin{tabular}{|l|l|l|l|l|l|l|}
\hline & CT1 & PT1 & CT2 & PT2 & CT3 & PT3 \\
\hline $\begin{array}{l}\text { Total No. } \\
\text { LREs }\end{array}$ & 57 & 64 & 26 & 24 & 17 & 33 \\
\hline $\begin{array}{l}\text { HQC } \\
\text { Episodes }\end{array}$ & 16 & 21 & 11 & 5 & 1 & 11 \\
\hline $\begin{array}{l}\text { MG } \\
\text { Episodes }\end{array}$ & 3 & 5 & 5 & 2 & 0 & 7 \\
\hline
\end{tabular}

These tables and figures are discussed in the following sections.

\section{Task 1: Professionals Today}

In task 1, an interview reconstruction primarily based on gap filling, learners working on paper engaged in a higher percentage (67\%) of language related talk than learners working at the computer (59.5\%) whereas for task 2 the results were the opposite, there was a higher percentage of language related talk at the computer (66.5\%) than on paper (55.5\%). There is a sharp difference in task 3 where learners working on paper showed a much higher degree of language related talk (34\%) than learners at the computer (17.5\%). In task 1 the difference observed in relation to language related talk is more related to the amount of off-task conversation learners engaged in than to the medium itself. One of the computer dyads spent some of the task time socialising because they had never worked together before, and they obviously needed to establish a socio-affective rapport before they embarked on the task. The other computer-based dyad who also spent some time off-task also needed to do so, as they got slightly diverted from the task to talk about how to type in orthographic accents on the computer, and although this was not 
particularly important for one of the participants, the other one made recurrent efforts to find out throughout the session.

Consistently with the amount of language related talk, more LREs were identified in the dialogue of paper-based learners (64) than in computer-based ones (57, see Table 1 and Table 2 above). Of particular importance, however, is the amount of HQC and microgenetic episodes (MGEs) identified in task 1. Learners working on paper coconstructed 21 HQC episodes (HQCEs) of which 5 were considered microgenesis, and these figures were 16 and 3 respectively for learners working at the computer. The computer played a limited role in the learners' collaborative achievement of HQC. In the case of HQC constructed around targeted items, i.e. pronouns, infinitive verbs, radical changing verbs, and ser versus estar, learners had access to immediate feedback from the machine, which could be potentially valuable to reinforce the recently constructed knowledge. Furthermore, in a minority of targeted HQC items, negative feedback from the computer made the learners continue working on those items. However, the teacher actually scaffolded 4 out of the 16 HQC episodes at the computer and 7 out of 21 in the paper-based version. There were no considerable differences in relation to task-related talk in this task between the two mediums.

Task 2: Gifted Daughters

Learners' talk in Task 2, the macro problem-solving task based on micro problem-solving linguistic exercises such as translation, gap filling, caption writing, and jumbled 
sentences, shows interesting differences between the mediums. The percentage of language related talk (see Table 1 above) was higher at the computer (66.5\%) than on paper (55.5\%). In spite of this, the amount of LREs is very similar in the two mediums (see Table 2: HQC comparison), 26 at the computer versus 24 on paper). There is, however, a clear difference in relation to HQC with computer-based learners able to coconstruct $11 \mathrm{HQC}$ episodes out of which 5 were identified as MGEs. In the case of learners working on paper, they only constructed 5 HQC which included 2 MGEs. The machine played an important role in this kind of task; first of all, the availability of immediate feedback on demand meant that learners did not have to wait for the teacher to check their work and provide subsequent clues and exercises which was the case for paper-based learners. Secondly, the specific kind of computer feedback provided, combined with the nature of the sub-tasks, encouraged learners to stretch their interlanguage and continue working on erroneous items, which in time led to a considerable amount of reflective talk and also contributed to 3 out of 5 MGEs. Precisely because of the importance of computer feedback hereby highlighted, special care needs to be accorded to the kind of feedback programmed in the task since there were also occasions where feedback created some confusion, e.g. the non-acceptance of a sentence because it was lacking a full stop. Finally, this particular task design gave computerbased learners more control and freedom as to how and when they wanted to tackle the macro problem-solving task. Paper-based learners did not have this choice, pace and range of "working tools", e.g. further exercises provided by the teacher, were dependent on the teacher's availability. 
In terms of task-related talk, the higher percentage identified in the paper-based protocols ( $41.5 \%$ versus $29.5 \%$ for computer learners) was related to the following two main reasons: first of all, learners spent more time trying to figure out what they had to do to carry out the task in spite of having exactly the same instructions as their computer counterparts. Secondly, as outlined above, they spent longer working on the macro problem-solving task than learners at the computer. The indexes of off-task talk were very low in both mediums; the only dyad at the computer that engaged in off-task conversation did so at the beginning of the task because they had not worked together before. Off-task talk in the paper version was caused by learners having to wait for the teacher to provide feedback.

\section{Task 3: Mexico City}

For this task learners had to read a short text about Mexico City, and then reconstruct it. They also had a subsequent sub-task where they had to write a similar text about London. This task was the least successful of the three research tasks, with only one group out of four benefiting from it linguistically. Furthermore, its implementation on the computer fundamentally influenced the nature of activity away from language learning. The percentage of language related talk for the learners working at the computer was low, only $17.5 \%$ versus $34 \%$ for learners working on the paper version, and there was only 1 computer-based HQC episode (see Table 1 and Table 2: HQC comparison). The direct effect of the computer on the way learners interpreted and implemented the tasks was caused by the use of boxes to hold each word. The rationale for the design was to 
promote the use of key content words, such as the name of city symbols, as the basis for language discussion about grammar words to make sense of the content and recreate the text. However, the appearance of boxes on the monitor encouraged a mnemonic approach throughout the whole session because learners knew they needed to "remember" the text exactly as they had read it for the computer to accept it. Piper reports similar behaviour when referring to the talk of learners working on a COPYWRITE task: "[learners] are seeking to call up the words mainly from their memory” (Piper, 1986: 192). This software is based exactly on the same principle as our task 3, learners read a text on screen and then try to reconstruct it with no help, but with dashes representing words. I believe that the fact that learners read the text instead of listening to it, as it is normally implemented in traditional dictogloss, also appealed to a reproduction of a seen "object" from memory rather than a reconstruction of a heard "text" which would be more difficult to reproduce exactly.

The dyad working on the paper version also followed a memory approach -even when they did not worry much about the spaces provided for words on their sheet- and these learners also kept very close to the original text when they wrote their own text about London. Neither of the two dyads at the computer finished the reconstruction task. The triad working on paper approached the task from a more creative perspective which produced the best results, $45 \%$ of language related talk, and 9 HQC episodes that included 7 MGEs, more - as a group - than any of the other dyads/groups across the three tasks. The results from this successful triad bear resemblance to the kind of activity reported by Swain and Lapkin (2001), whose dictogloss students focused on form while 
discussing their language problems, "brought to conscious attention gaps in their own knowledge”, engaged in hypothesis testing and built on each other's resources (2001:110).

The fact that language related work at the computer (17 LREs in total, which included 1 HQC episode) did not provide learners with opportunities to stretch their interlanguage and co-create zones of proximal development also reflects the nature of learners' activity. They were working from the memory of a recently read text, and the language they focused on was either within their memory grasp where they were making spelling corrections, for instance, or simply involved self-corrections. Even the limited amount of LREs (3) where learners engaged in some reflective activity and could have potentially led to some creative use of vocabulary, for instance, was cut short by the sudden recollection of a word in the text, ending thus the creative exploration they had initially embarked on. The delivery of this task via the computer meant a task transformation from "open" - as the paper version was - into "closed" where the gaps of the computer required discrete, precise information (cf. Loschky and Bley-Vroman, 1993).

Task-related talk, which represented a large percentage in both modes of implementation, $75 \%$ for computer-based and $64.5 \%$ for paper-based interaction, was - as language related talk - qualitatively different. Learners at the computer engaged in more meta-task commentary, as well as planning how to tackle the exercise, whereas learners on the paper version engaged in more task-implementation talk. Text reconstruction was supported by cumulative repetition, for instance, without necessarily focusing on form 
while doing so. Off-task conversation, $7.5 \%$ at the computer, was related to keyboard combinations to type orthographic accents, and some socialisation. The minimal off-task percentage among learners working on paper (1.5\%) was an interesting mini-discussion brought up by the general topic of cities that was the basis for their activity.

\section{Conclusions}

Sociocultural theory has provided theoretical and methodological foundations in this study to investigate pair/group interaction at the computer and the impact of the machine upon collaborative activity. A core premise underlying the investigation is that dialogic activity has the potential to support cognitive and linguistic development (cf. Swain 1997; Swain and Lapkin, 2001). However, not all dialogue is collaborative dialogue (i.e., "where language use and language learning can co-occur", Swain, 2000: 97) and we need to gather more information to understand the inter-psychological basis for the adequate promotion of the latter. The type of task learners engage in and the influence of the medium, that is computer or paper, on interaction also need addressing if we are going to provide better opportunities for learners in classrooms where computers are increasingly being used. Variability across the dyads/groups in terms of performance highlights the need to evaluate and discuss tasks as blueprints for activity (cf. Coughlan and Duff, 1994). The results of this study therefore reflect the activity that took place among specific learners under specific circumstances. 
Keeping the above observations in mind, and to summarise the findings in relation to the research questions posed at the beginning of the study, I believe the dictogloss version was the least successful of the three tasks, and when implemented at the computer, it was a very limited source for language related activity. In its paper version, however, the motivation and creative approach of a group of participants made of the task a meaning making experience. Task 1 supported the highest number of HQC episodes and proved to have certain useful features, such as the opportunity for learners to explore their own ideas and stretch their interlanguage in order to express them; the main gap-filling format provided opportunities for form focused discussions even when this type of exercise could have led to its individual resolution. A downside of this task was the requirement for learners to work on gap-filling for too long; this, I believe, undermined learners' efforts to make a better use of the semantic and syntactic context surrounding the gaps. The integration of macro and micro problem-solving endeavours in task 2 showed mixed results. Most learners did not find the macro problem-solving task relevant to their language class and therefore relegated it as an exercise to do after the "proper" work on language. Based on this study and other reports on the use of problem-solving tasks that are not obviously language oriented (see comments about "Lemonade Stand” in Abraham and Liou, 1991) I also believe caution needs to be observed not to cognitively overload learners to a degree where the concern for linguistic activity is overshadowed. In relation to the micro problem-solving tasks based on language, the translation and caption writing exercises were the most successful in task 2, with jumbled sentences being the least linguistically motivating. Even when learners are expected to work at syntactic level in order to create meaningful sentences, there is very little evidence that they do so, and the 
drag and drop facility (very popular in commercial CALL programmes) when this task is implemented via the computer invites, in my view, a trial-and-error approach.

Drawing on Sociocultural Theory to study interaction and collaboration in the language classroom is a concept still in its infancy. The kind of developmental analysis promoted by Vygotsky as a means to explore cognitive development needs to be cautiously explored and refined when applied to the study of second language development. In this article, I have advanced an analytical unit, High Quality Collaboration (HQC) to investigate the co-construction of language related knowledge among learners working on paper and computer-based tasks. This unit has allowed qualitative analysis of interaction as well as quantification for comparative purposes. More specifically, HQC episodes have enabled the study of knowledge co-construction between learners even when some episodes cannot be strictly classified as microgenetic ones. Undoubtedly, this unit of analysis will have to be further tested to assess its value as a methodological tool in other studies.

\section{Acknowledgements}

I would like to thank Phil Scholfield for his insightful comments. Any errors remain solely my own.

\section{References}

Abraham, R. G. and Liou, H. (1991) Interaction Generated by Three Computer Programs: Analysis of Functions of Spoken Language. In Dunkel, P. ComputerAssisted Language Learning and Testing: Research issues and Practice. New York: Harper Collins, pp. 85-109. 
Adobe GoLive: Web authoring package - see Products / Web publishing: http://www.adobe.com

Arneill S., Holmes M. \& Street H. (1998) Hot Potatoes, Victoria, Canada: University of Victoria: http://web.uvic.ca/hrd/halfbaked

Author (2004) The Processes of Collaborative Activity in Computer-Mediated tasks: in Search of Microgenesis. Unpublished doctoral dissertation, University of Southampton.

Coughlan, P. and Duff, P. A. (1994) Same Task, Different Activities: Analysis of SLA Task from and Activity Theory Perspective. In Lantolf, P. and Appel, G. (eds.), Vygotskian Approaches to Second Language Research. Norwood, NJ: Ablex.

Daniels, H. (1993) Charting the Agenda: Educational Activity after Vygotsky. London: Routledge.

Donato, R. (1988) Beyond group: A psycholinguistic rationale for collectivity in second language learning. Unpublished doctoral dissertation, University of Delaware.

Donato, R. (2000) Sociocultural contributions to understanding the foreign and second language classroom. In Lantolf, J. P. (ed.) Sociocultural Theory and Second Language Learning. Oxford: Oxford University Press, pp. 27-50.

Fortune, A. and Thorp, D. (2001) Knotted and Entangled: New Light on the Identification, Classification and Value of Language Related Episodes in Collaborative Output Tasks. Language Awareness, 10(2/3): 143-160.

Hoven, D. (1999) CALL-ing the learner into focus: towards a learner-centred model. In Debski, R. and Levy, M. (eds.), WorldCALL: Global perspectives on computerassisted language learning. Lisse: Swets \& Zeitlinger.

Kowal, M. and Swain, M. (1997) From semantic to syntactic processing. How can we promote it in the immersion classroom? In Johnson, R. K. and Swain, M. (eds.), Immersion Education: International Perspectives. Cambridge: Cambridge University Press, pp. 284-309.

Lantolf, P., \& Appel, G. (1994) (eds). Vygotskian Approaches to Second Language Research. Norwood, NJ: Ablex.

Long, M. H. (1983a). Native speaker/non-native speaker conversation and the negotiation of comprehensible input. Applied Linguistics, 4(2): 126-141.

Long, M. H. (1983b). Linguistic and conversational adjustments of non-native speakers. Studies in Second Language Acquisition, 5: 177-193.

Loschky, L. \& Bley-Vroman, R. (1993). Grammar and task-based methodology. In G. Crookes \& S. Gass (eds). Tasks and Language Learning: Integrating Theory and Practice. Clevedon, England: Multilingual Matters Ltd, pp. 123-167.

Mitchell, R. and Myles, F. (2004) Second Language Learning Theories. London: Arnold.

Ohta, A. S. (2000) Rethinking interaction in SLA: Developmentally appropriate assistance in the zone of proximal development and the acquisition of L2 grammar. In Lantolf, J. P. (ed.), Sociocultural Theory and Second Language Learning. Oxford: Oxford University Press, pp. 51-78.

Ohta, A. S. (2001) Second language acquisition processes in the classroom: Learning Japanese. Mahwah, NJ: Lawrence Erlbaum.

Pica, T. (1994) Research on negotiation: what does it reveal about second language learning conditions, processes and outcomes? Language Learning 44: 493-527. 
Piper, A. (1986) Conversation and the computer: a study of the conversational spin-off generated among learners of English as a second language working in groups. System, 14: 187-198.

Richards, T. and Richards, L. N5 Package for Qualitative Data Analysis from QSR. University of Western Sydney.

Roschelle, J.and Teasley, S. D. (1995) The Construction of Shared Knowledge in Collaborative Problem Solving. In O’Malley, C. (ed.), Computer Supported Collaborative Learning. Berlin: Springer-Verlag, pp. 69-97.

Roebuck, R. (2000) Subjects speak out: How learners position themselves in a psycholinguistic task. In Lantolf, J. P. (ed.), Sociocultural Theory and Second Language Learning. Oxford: Oxford University Press, pp. 79-95.

Swain, M. (1995) Three functions of output in second language learning. In Cook, G. and Seidlhofer, B. (eds.) Principle and Practice in Applied Linguistics. Oxford: Oxford University Press, pp. 245-256.

Swain, M. (1997) Collaborative dialogue: Its contribution to second language learning. Revista Canaria de Estudios Ingleses, 34: 115-132.

Swain, M. (1998) Focus on form through conscious reflection. In Doughty, C. and Williams, J. (eds.), Focus on Form in Classroom Second Language Acquisition. Cambridge: Cambridge University Press, pp. $64-81$.

Swain, M. (2000) The output hypothesis and beyond. In Lantolf, J. P. (ed.), Sociocultural Theory and Second Language Learning, Oxford: Oxford University Press, pp. 97-114

Swain, M., and Lapkin, S. (1995). Problems in output and the cognitive processes they generate: a step towards second language learning. Applied Linguistics 16 (3): 371-391.

Swain, M. and Lapkin, S. (2001) Focus on form through collaborative dialogue: Exploring task effects. In Bygate, M., Skehan, P., and Swain, M. (eds.), Researching Pedagogic Tasks: Second Language Learning, Teaching and Testing. London: Longman, pp. 99-118.

Vygotsky, L. S. (1978). Mind in society: the development of higher psychological processes. Cambridge, MA: Harvard University Press.

Wertsch, J. V. (1985) Vygotsky and the Social Formation of Mind. Cambridge, MA: Harvard University Press. 